\title{
Experiential Pluralism and the Power of Perception
}

\author{
Mark Eli Kalderon \\ April I, 2OI2
}

Things go wrong, as we really all know quite well, in lots of different ways

Austin

\section{Introduction}

Sight is for the sake of seeing. That thought animates the tragedy that befalls $\mathrm{Clau}^{-}$ dia Menlo, played by Joan Crawford, in a segment of the first episode of The Night Gallery entitled "Eyes". Claudia Menlo is a wealthy blind woman who undergoes an experimental eye transplant, with eyes illegally purchased from an impoverished gambler. The effects of the procedure are brief. Claudia will be able to see for only a few hours. To make the most of her fleeting capacity for sight, Claudia has filled her apartment with great works of art. However, alone in her apartment, after the surgery, but before her bandages are removed, a blackout occurs, and her sight only persists until first light. Her fate is tragic insofar as her sight, acquired by sacrificing the humanity in another, is wasted. But this could only be so if sight is for the sake of seeing.

Reflection on this forms the basis of an argument for experiential pluralism. Cambridge realists, such as Moore (I953), Russell (I9I2), and Price (I932), maintained that all sense experience, and not just perception, involves a sensory mode of awareness. Cambridge realists were thus committed to a kind of experiential monism (in Snowdon's 2008 terminology). Specifically, all sense experience involves, as part of its nature, a sensory mode of awareness. Even subject to illusion or hallucination, there is something of which one is aware. And with that, 
they were an application of the argument from illusion, or hallucination, or conflicting appearances away from immaterial sense data and a representative realism that tended, over time, to devolve into a form of phenomenalism. If experiential monism is the claim that experience has a single common nature, then experiential pluralism is its denial. Drawing upon the distinct tradition of Oxford realism, Travis $(2005 \mathrm{~b})$, in contrast, defends disjunctivism and, thus, a kind of experiential pluralism. Perception may be sensory mode of awareness, but not all sense experience, involves, as part of its nature, an awareness of something.

Sight is a capacity, and seeing is its exercise. Reflection on the sense in which sight is for the sake of seeing reveals distinct relations of dependence between sight and seeing, the capacity and its exercise. Moreover, these relations of dependence in turn reveal the nature of our perceptual capacities and their exercise. Specifically, if sight is for the sake of seeing, then sight will depend, in a certain sense, upon seeing, in a manner inconsistent with experiential monism. Thus reflection on the power of perception forms the basis of an argument for experiential pluralism.

\section{The Stuff-Happens Model}

In 'The Inward Turn', Travis introduces the Stuff-Happens model as follows:

No one, I think, thinks there is any sense of 'see' in which merely to have something 'affect your eyes'-say, form retinal images-is to see it. Why not? A natural, though not inevitable, idea is: before one saw anything, more stuff would have to happen. ... A further natural idea might then be: at a certain point the relevant stuff, or enough of it, has happened. At that point, the perceiver goes into a certain 'internal' state, the upshot of the stuff, where this is one of a specified range of states into which a particular device, 'that which enables vision', might go. In such a state, the idea is, one enjoys visual awareness (or experience). One sees only in enjoying visual awareness. The state decides what visually awareness one thus enjoys; thus, at least, what it is in which one might be seeing something. (Travis, 2009, 315)

The Stuff-Happens model is widely subscribed to. Arguably, Evans (I982) and Burge (2OIO) count among its advocates. However, when initially confronted with Travis' bald description of it, I immediately felt that the model left something important out of account. I now recognize what that is. The Stuff-Happens model doesn't take seriously enough that sight is a perceptual capacity.

On the Stuff-Happens model, proximal stimulation of sensory transducers sets off a sequence of alterations within the perceiver. At the end of this process, the perceptual system is in a certain state. The perceiver with a perceptual system in 
this state enjoys a particular sensory awareness. The terminal state of the sequence of alterations initiated by the proximal stimulation of sensory transducers deter mines the perceptual experience the perceiver undergoes. So conceived, perceptual experience is a conscious alteration of the perceiving subject.

But the exercise of a capacity is not, or not merely, an alteration. If an object undergoes an alteration, it becomes other than what it was. Consider a tomato altering its color as it ripens, from green to red, say. Red and green are contraries. Prior to the alteration, the tomato was green and not red; after the alteration, the tomato is red and not green. The exercise of a capacity is crucially different. Aristotle describes the difference as follows:

Being affected is not a single thing either; it is first a kind of destruction of something by its contrary, and second it is rather the preservation of that which is so potentially by that which is so actually and is like it in the way that a potentiality may be like an actuality. ... For this reason it is not right to say that something which understands is altered when it understands, any more than a builder when he builds. (Aristotle, De Anima II 5 4I $7^{b} f f$; Hamlyn 2002, 23-24)

A builder doesn't cease to be a builder in building a house; rather, he realizes his nature as a builder. To be a builder is to potentially build, and this potentiality is preserved when actually building. Similarly a thinker doesn't cease to be a thinker in thinking a thought. To be a thinker is to potentially think, and this potentiality is preserved when actually thinking. Of course, in building a house, the builder will undergo various alterations. When hammering, intrinsic shape changes over time. And it is true that without undergoing some such alterations, neither builder nor thinker could exercise their capacities. However, the exercise of a capacity is more than being subject to various alterations. It is more than the destruction of something by its contrary. It essentially involves the preservation and actualization of a potentiality.

It is this aspect of capacity exercise that the Stuff-Happens model leaves out of account. In maintaining that the terminal state of the sequence of alterations deter mines the perceptual experience that the perceiver undergoes, the Stuff-Happens model maintains that the exercise of our perceptual capacities is nothing more than the conscious alteration of the perceiving subject. But sight is a capacity, the capacity to see. Capacities are a species of potentiality, a potential actualized in their exercise. Seeing the scene involves the preservation and actualization of a potential for such seeing. In seeing the scene before them, the subject exercises their perceptual capacities and so realizes their nature as a perceiver.

The point can be obscured for us in two ways.

The first way involves the natural history of perception. A given episode of perception - seeing a pig in plain view, say — is part of the causal order and, as such, 
has a natural history. The proximal stimulation of the subject's sensory transducers - the forming of retinal images - is part of the natural history of that perception, as is the subsequent, cascading effects of further visual processing. Perception has a natural history. As such, stuff has to happen in order for the subject to be in a position to perceive what is in plain view. Only a magical theory of perception (or an Hegelian astromoner) would maintain otherwise, as Burge (2005) has been keen to emphasize. But it doesn't follow that what we perceptually experience is determined by an internal state that the perceptual system goes into having processed the proximal stimulation (see Campbell, 20IO; McDowell, 20Iо; Travis, 20II). Perception may require that stuff happens, but if an episode of seeing is the exercise of the subject's perceptual capacities, then it is not, or not merely, a conscious alteration of the perceiving subject.

The second way involves perceptual capacities being capacities of a distinctive kind. In Nietzsche's (I887) terminology, they are reactive capacities. Perceptual capacities only act by reacting to the presence of a sensible particular. Aristotle makes this point by means of an analogy with combustion:

The question arises as to why we have no sensation of the senses themselves; that is, why they give no sensation apart from external objects, although they contain fire and earth and the other elements which (either in themselves, or by their attributes) excite sensation. It is clear from this that the faculty of sensation has no actual but only potential existence. So it is like the case of fuel, which does not burn by itself without something to set fire to it; for otherwise it would burn itself, and would not need any fire actually at work. (De Anima II $54 \mathrm{I}^{a} 3^{-}{ }^{-\mathrm{IO}}$ )

The presence of the sensible particular ignites sensory consciousness. Perception is essentially a reactive capacity, otherwise it would not be a mode of sensitivity to external particulars and their sensible qualities and relations. Perception differ in this way from our epistemic capacities. The exercise of our epistemic capacities does not, in general, require the presence of any particular. One can know that the sun is burning white even when night has fallen and the sun is absent. Our epistemic capacities are thus not a mode of sensitivity to external particulars and their sensible qualities and relations. Our epistemic capacities do not act by reacting. They are active, not reactive. Whereas we can choose to exercise our knowledge in a given circumstance, we are subject to what we perceive (see Aristotle, $D e A n^{-}$ ima II $54 \mathrm{I}^{b}$ ). Kantians would describe this difference between perception and knowledge as a difference between the exercise of receptivity and spontaneity, respectively.

Perception is a reactive capacity, and this means that the perceiver must be acted upon in order to exercise their perceptual capacity. In the case of vision, this will 
involve retinal stimulation and the cascading effects of subsequent visual processing. But, again, just because stuff's happening is a material precondition for seeing doesn't mean that seeing isn't the exercise of a perceptual capacity in a manner inconsistent with its merely being a conscious alteration of the perceiving subject. Stuff's got to happen in order to see, but perception is the exercise of a capacity triggered by, if not identified with, stuff's happening.

\section{Capacities and the Metaphysics of Perception}

McDowell (2OIO) has recently emphasized the importance of acknowledging that perceptual experience is the exercise of a subject's perceptual capacities. He argues that unclarity about the relevant metaphysics leads Burge (2005) to an inadequate conception of perceptual fallibility, a conception from which he draws mistaken conclusions about the nature of perceptual warrant. Specifically, according to Burge, perception, understood as an individual perceptual episode, is fallible. And since individual perceptual episodes are fallible, what warrant they provide must be defeasible. However, McDowell maintains that this line of reasoning is undermined by an initial misstep concerning the metaphysics of perceptual capacities:

Fallibility is a property that attaches to capacities. It is a confusion to think that the idea of fallibility can intelligibly carry over to exercises of fallible capacities ... And it is not much of an improvement if, in the case of fallible capacities to achieve warrant, the confused idea that it makes sense to attribute fallibility to their exercises is replaced by the idea that their exercises cannot yield better than defeasible warrant. (McDowell, 2010, 245)

It is perceptual capacities and not their exercise that are fallible. In propitious circumstances, the exercise of subject's perceptual capacities may make some aspect of the natural environment present to them. Moreover, there is no possibility compatible with the subject's perceptual experience being what it is that the subject could be wrong in thinking that the natural environment is as their experience presents it to be (McDowell 20IO, 245; see Brewer 20II, Johnston 2006, 20II, Kalderon 20II, Kalderon and Travis forthcoming, Travis 2005a for variations on this idea). And it is natural to suppose that this is the basis of an indefeasible warrant for the corresponding perceptual judgment. Nevertheless, perception, understood not as an individual perceptual episode, but as a perceptual capacity, may be fallible. The 'non-defective' exercise of the subject's perceptual capacities may make the environment present to the subject in a manner inconsistent with the falsity of the corresponding perceptual judgment, but not all exercises of the 
subject's perceptual capacities are non-defective in this way. Sight misfires when induced to make the subject hallucinate. McDowell offers the following analogy:

Some people have a capacity to throw a basketball through the hoop from the free-throw line. Any instantiation of such a capacity is imperfect; even the best players do not make all their free throws. Burge thinks that there cannot be a fallible capacity in whose non-defective exercises one gets to have indefeasible warrant for certain beliefs. One might as well think that there cannot be a capacity - of course not guaranteed success on all occasions - in whose non-defective exercises one actually makes free throws. (McDowell, 2010, 245-6)

McDowell's criticism of Burge emphasizes the importance of acknowledging that perceptual experience is the exercise of a subject's perceptual capacities. We gain a better understanding of the nature of perceptual capacities and their exercise by examining the relations of dependence that obtain among them.

\section{Modal-Existential Dependence}

Sight is a capacity, and seeing is its exercise. What is the relationship between sight and seeing, the capacity and its exercise?

Begin with a flat-footed thought. Sight enables a subject to see. If the subject lacked sight, the subject could not see the scene before them. Lacking sight is an excellent explanation for why a particular subject did not see some salient aspect of the distal environment. The subject's seeing the scene before them seems to depend, in a straightforward way, upon the subject's possessing the capacity for sight. Specifically the existence of a given episode of seeing depends upon the existence of the subject's capacity for sight. Moreover, this dependency is modal in character: Necessarily, if the subject sees the scene before them, then the subject possesses the capacity for sight. Seeing modal-existentially depends upon sight:

One thing $x$ will [modal-existentially] depend upon another $y$ just in case it is necessary that $y$ exists if $x$ exists (or in the symbolism of modal logic, $\square(E x \rightarrow E y)$ ). (Fine, I995, 270)

Ricca's smile depends, in this sense, upon Ricca. Necessarily, if Ricca's smile exists, then so does Ricca. Thus particularized features or tropes modal-existentially depend upon the particulars whose features they are. The definition characterizes a family of modal-existential dependencies with different interpretations of the operative modality - metaphysical or nomological, say-yielding different notions of modal-existential dependence. The notion of modal-existential dependence at work in the claim that seeing modal-existentially depends upon sight is the one that 
results from interpreting the operative modality as metaphysical necessity. Fine (I995) has shown that existential dependence is not modal-existential dependence. (Socrates modal-existentially depends but does not existentially depend upon his singleton.) Nevertheless, it is metaphysically relevant that seeing not only existentially depends but modal-existentially depends upon sight.

The modal-existential dependence of seeing upon sight is an instance of a more general phenomenon, the modal-existential dependence of the exercise of a capacity upon the possession of that capacity. Arguably, this is a consequence of the modal nature of capacities. A capacity is a kind of potentiality. If a subject has a capacity to do something, they have the potential to do that thing. A subject with a perceptual capacity is a potential perceiver. Necessarily, if, in propitious circumstances, the subject in fact sees something, then it was possible for them to see that thing. After all, if it wasn't possible for them to see that thing, they wouldn't actually see it. But this is just the modal-existential dependence of an exercise of a capacity on the capacity whose exercise it is.

A subject has the potential to perceive because they have the power to perceive. Seeing is possible for a subject because the subject has the power to see the scene before them. A subject has that power in part because of the functional organization of their perceptual system. Though only in part. The subject's power to perceive the natural environment will depend, as well, upon the nature of that environment and the subject's relation to it (on relational explanans see Peacocke r993; Williamson 2000). So the potential that seeing modal-existentially depends upon is itself grounded in the power of perception.

Modal-existential dependence, so defined, is not asymmetric in the sense of being antisymmetric and irreflexive. There is no logical reason why there shouldn't be a species of modal-existential interdependence, or if this does not come to the same thing, codependence, obtaining among a system of entities, perhaps of cor relative kinds. Given this, we can define a stronger notion of modal-existential priority in terms of asymmetric modal-existential dependence:

$x$ is modal-existentially prior to $y \leftrightarrow y$ modal-existentially depends upon $x$, but $x$ does not modal-existentially depend upon $y$.

The matter of at least some material compounds are modal-existentially prior to those compounds. Necessarily, if a sand castle exists, then so does the sand that composes it. But the converse is not the case. So sand is modal-existentially prior to sand castles.

Seeing modal-existentially depends upon sight. Is sight modal-existentially prior to seeing? To establish this, it would suffice to show that sight does not modalexistentially depend upon seeing. This amounts to the possibility that a subject possesses the capacity for sight, but there is no episode of seeing which is its exercise. But that is certainly possible: Perhaps the hapless subject is blindfolded, 
or unconscious, or, like Claudia Menlo, shrouded in darkness. So not only does seeing modal-existentially depend upon sight, but sight is modal-existentially prior to seeing as well.

Is it true more generally that a capacity is modal-existentially prior to its exercise? The acquisition and persistence of some capacities raises a doubt about this more general claim.

How is it that a person can come to acquire the capacity to play the piano? Unless one is a preternatural prodigy, one learns to play the piano by, well, playing the piano. One acquires that capacity by repeatedly performing the activity which is its exercise. And if one fails to repeatedly perform the activity which is its exercise, then one would not acquire the capacity to play the piano. But this suggests, that the capacity to play the piano modal-existentially depends upon playing the piano. If possessing the capacity to play the piano modal-existentially depends upon playing the piano, then the capacity to play is not modal-existentially prior to playing.

This argument is subject to the following criticism: The first stumbling attempts to play, are they really playing? Struggling through a scale or elementary piece of music (chopsticks, say) may count as playing, at least on one standard for playing-keys are moved and sounds issue forth. But such activity is not or not yet the exercise of a capacity. On a more restricted standard for playing that requires playing to be the exercise of a capacity to play, the first stumbling attempts to play don't count as playing. They are not the exercise of a mastery, however limited, of an instrument. At best they are a surrogate for playing engaged in so as to acquire the capacity to genuinely play. But if the activity that the capacity to play modalexistentially depends upon is not itself the exercise of a capacity, then this goes no way towards showing that, the capacity to play is not modal-existentially prior to playing (though compare Aristotle's brief remarks at Metaphysics $\Theta 8 \mathrm{IO}_{5} \mathrm{O}^{a} \mathrm{I}^{-}{ }^{-}{ }_{4}$ ).

Another argument, not subject to this criticism, involves not the acquisition but the persistence of a capacity. For the capacity to play the piano to persist, for it to continue to exist, it must be exercised at more or less regular intervals. Sadly, it is possible to lose this capacity, simply by neglecting to exercise it. But again this suggests that the continued existence of the capacity depends upon the existence of its exercise at regular intervals, that the capacity to play the piano modal-existentially depends upon playing the piano. Since what is at issue is the persistence of the capacity, there is no question that the activity that the capacity modal-existentially depends upon is the exercise of that capacity (as there was in the case of its acquisition). But if the capacity to play the piano modal-existentially depends upon playing the piano (understood in the strict sense of an exercise of a mastery of the instrument), then the capacity to play is not modal-existentially prior to playing. This is a kind of modal-existential interdependence between a capacity and its exercise. So while sight is modal-existentially prior to seeing, it is 
not true in general that capacities are modal-existentially prior to their exercise.

\section{Ontological Dependence}

Sight is a sensory capacity that a subject may have or lack. Having the capacity for sight is a way for a subject to be. This way for a subject to be differs from having the capacity for audition or olfaction, on the one hand, and having nonsensory capacities, such as the capacity to compute prime numbers, on the other. Having the capacity for sight differs as well from other ways of being that aren't themselves the possession of a capacity. Sight is a way of being, and insight into its nature is gained when we recognize that there is a sense in which sight depends upon seeing. Given that sight is modal-existentially prior to seeing, the dependence of sight upon seeing could not be modal-existential dependence. Rather, it must be a distinct notion of dependence, and one that is compatible with the modalexistential priority of sight.

Begin with the thought, to be subsequently qualified, that capacities are individuated by their exercise. The capacity to play the piano differs from the capacity to speak Japanese given the distinctive nature of its exercise. Arguably this is a consequence of the modal nature of capacities. Capacities are a kind of potentiality, and potentialities are distinguished by what they are the potential for. Sight is a potential for seeing, just as audition is the potential for hearing. And they differ in what they are the potential for, seeing and hearing, respectively.

Possessing the capacity for sight is a way of being. And what it is to be that way is to have the potential to undergo episodes of seeing. The thought is not that sight modal-existentially depends upon seeing-Claudia Menlo acquires sight and yet sees nothing. Rather, what it is for a subject to possess a capacity, a particular way of being, depends upon what it is for something to be its exercise, a distinct, if related, way of being. Possessing the capacity for sight is a state of the subject, whereas seeing, its exercise, is episodic - it is something the subject undergoes. These are distinct ways of being with distinct temporal profiles. Whereas a state is wholly present at each time in the temporal interval through which it persists, an event unfolds through a temporal interval and is not wholly present at each time in that interval. Possessing the capacity for sight is a particular way being, a state of a subject that consists in the potential to undergo episodes of seeing, a distinct way of being, not a state of the subject but something the subject undergoes.

Existence is one thing, being is another. Merely determining the existence of something is not yet to determine what it is to be that thing even if that thing must be some way if it is to exist at all. Moreover, there are ways for something to be which no thing is. Similarly, Fine writes:

For it does not seem right to identify the 'being' of an object, its being 
what it is, with its existence. In one respect, existence is too weak; for there is more to what an object is than its mere existence. In another respect, existence is too strong; for what an object is, its nature, need not include existence as a part. (Fine, 1995, 274)

Having the capacity for sight is a way for a subject to be. And what it is to be that way is to have the potential to undergo episodes of seeing. This is not the modal-existential dependence of sight on seeing, that would be inconsistent with the modal-existential priority of sight. Rather, sight ontologically depends upon seeing in that what it is to possess that capacity depends upon what it is to undergo an episode of seeing. The individuation of capacities by their exercise is a manifestation of the ontological dependence of the former upon the latter.

Not only does ontological dependence differ from modal-existential dependence in lacking its existential character, but ontological dependence also lacks its modal character. The relevant notion of dependence is more fine-grained than necessary co-instantiation of ways of being (see Fine, 1994, I995; Schaffer, 2009; Rosen, 20IO). Being Socrates is a way for things to be, and indeed a way that Socrates actually was. Being Socrates is necessarily co-instantiated with being co-present with 17 (on the assumption that I7 exists necessarily). Necessarily, if anything instantiates that way for something to be, namely, being Socrates, it also instantiates

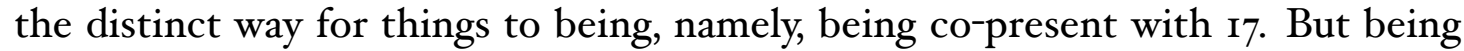
Socrates does not ontologically depend upon being co-present with I7. It is no part of Socrates' nature, no part of what it is to be Socrates, that something which is Socrates bears the relation of co-presence with an arithmetical entity, even if this is necessarily the case. Whereas modal-existential dependence is intensional, ontological dependence is hyperintensional.

Since ontological dependence is distinct in these ways from modal-existential dependence, the ontological dependence of one thing upon another is consistent with the converse modal-existential dependence. Thus sight may ontologically depend upon seeing, even as seeing modal-existentially depends upon sight.

Just as modal-existential priority was defined in terms of asymmetric modalexistential dependence, there is a corresponding notion of ontological priority defined in terms of asymmetric ontological dependence:

$x$ is ontologically prior to $y \leftrightarrow y$ ontologically depends upon $x$, but $x$ does not ontologically depend upon $y$.

In Metaphysics $Z$ Io, Aristotle claims that right angles are prior to acute angles. This claim is puzzling if the relevant priority is interpreted as modal-existential priority. Right angles may be defined independently of acute angles, but they wouldn't exist, if acute angles did not also exist. The claim is more plausibly interpreted in terms 
of the ontological priority of right angles over acute angles. So interpreted, the order of definition parallels the order of being, at least in this instance.

Sight ontologically depends upon seeing. What it is to possess the capacity for sight depends upon what it is to undergo an episode of seeing. Is seeing ontologically prior to sight? To establish this, it would suffice to show that seeing does not ontologically depend upon sight. But the being of the latter wholly consists in the potential of a subject to undergo episodes of the former. Sight just is the potential to see. So not only does sight ontologically depend upon seeing, but seeing is ontologically prior to sight. This is plausibly an instance of a more general metaphysical principle, the ontological priority of the actual over the potential.

We began with the thought that capacities are individuated by their exercise. Rightly understood, I believe this claim to be true. What is needed for this understanding is greater clarity about what it is exactly that capacities ontologically depend upon. Sight ontologically depends upon seeing. But seeing isn't just any exercise of the subject's capacity for sight. It is, as McDowell (2010) puts it, a 'non-defective' exercise of the subject's perceptual capacity. After all, the subject's capacity for sight is equally drawn upon in its 'defective' exercise. Compare seeing a pig in plain view, a non-defective exercise of the subject's capacity for sight, with hallucinating that scene, a defective exercise of that capacity. In hallucinating that there is a pig before them the subject's capacity for sight is drawn upon even though their visual experience is not an episode of seeing a pig. Similarly, there are mistakes in playing the piano that only an experienced player so much as could make. In making these mistakes, the player draws upon their capacity to play. Perhaps capacities are individuated by, and so ontologically depend upon, not their exercise, understood unrestrictedly, but their non-defective exercise.

Why think that capacities ontologically depend upon their non-defective exercise? In hallucinating a pig, the subject's capacity for sight is drawn upon. In hallucinating a pig, the subject undergoes a visual experience that is the exercise, albeit a defective one, of the subject's capacity for sight. An explanation of the subject's hallucinatory experience would inevitably advert to their perceptual capacities and the manner in which they were drawn upon in giving rise to this experience. In hallucinating a pig, the subject's perceptual capacities are drawn upon in the sense that the hallucination is the effect of the subject's power to perceive, a power the subject has thanks to the functional organization of their perceptual system and the nature of the environment and their relation to is. And yet it would seem odd to say that their capacity for sight is fully manifest in so hallucinating. At the very least, the subject does not realize their nature as a perceiver in hallucinating a scene before them. It is more plausible to think that sight is fully manifest in seeing, that what it is to possess the capacity for sight consists in the subject's potential to undergo episodes of seeing, as opposed to undergoing experiences indiscriminable 
upon reflection from seeing (compare Martin, 2004, especially p. 72).

The tragedy that befell Claudia Menlo makes this vivid for us. Failing, unexer cised, at first light, her sight, purchased at the terrible cost of blinding another, was wasted. This could only be so if sight is for the sake of seeing. Thus Aristotle writes (Metaphysics $\Theta 8$ 1050 ${ }^{a}$ IO; Barnes I984) "For animals do not see in order that they may have sight, but they have sight that they may see." If sight is for the sake of seeing, then in failing to see, Claudia's capacity for sight goes unfulfilled. It is in this sense that it has gone to waste. The thought upon which this tragedy turns encouraged Aristotle to claim that seeing was a final cause. However, one need not accept the Aristotelian doctrine of final causation to accept that the function of the perceptual system is to enable the subject to perceive. This latter thought is consistent with a thoroughly naturalistic understanding of how the subject's per ceptual system helps determine their perceptual capacities. Indeed, according to Burge, this is the primary natural norm governing perception:

Some norms are natural norms. By 'natural norm' I do not mean naturalistically reducible norm. I mean a level of performance adequate to fulfill a function or a purposiveness, and that constitutes an explanatorily relevant kind, independently of any individual's having a positive or negative attitude toward the function or the norm.... The primary natural ... norm that is constitutively associated with perceptual capacity is to perceive things as they are ... (Burge, 2OIO, $3 \mathrm{II}^{-} 3 \mathrm{I}^{2}$ )

The proposal is that perceptual capacities ontologically depend upon their nondefective exercises and that we understand their non-defective exercises as that for the sake of which the subject possesses that capacity, namely, to perceive things as they are. Sight is a kind of potentiality. As such, what it is to possess that capacity depends upon what it is a potential for. The capacity for sight is drawn upon in giving rise to variety of visual experiences, not all of which are perceptual. But it is odd to claim that a subject's capacity for sight is fully manifest in hallucinating a scene, that sight is for undergoing experiences merely indiscriminable upon reflection from seeing. So it is implausible to suppose that sight ontologically depends upon its exercise, understood unrestrictedly. Rather sight ontologically depends upon its non-defective exercise, where the non-defective exercise of a perceptual capacity is that for sake of which the subject possesses that capacity, namely, to perceive. It is because the end of sight is immanent in seeing, that sight depends for its being upon the nature of seeing. 


\section{Ontological Priority and Experiential Pluralism}

Having the capacity for sight is a way for a subject to be. And what it is to be that way is to have the potential to undergo episodes of seeing. Sight thus ontologically depends upon seeing. What it is to possess this capacity depends upon what it is to undergo an episode of seeing. Moreover, it wholly depends upon what it is to undergo an episode of seeing. (Thus are the wages of ontological priority.) What it is to undergo an episode of seeing is a way for a subject to be, but what way is that?

A comparison with knowledge is instructive. Knowledge is factive. If a subject knows something, there is some fact that the subject knows. If there is no fact that the subject knows, then the subject fails to know anything. Correspondingly, if a subject sees something, there is something that the subject sees. If there is nothing that the subject sees, then the subject fails to see anything. Undergoing an episode of seeing is a way for a subject to be, and part of what it is to be that way is for there to be something that is the object of perception. The function of the perceptual system is to enable the subject to perceive some sensible aspect of the natural environment. So the end of sight, that for the sake of which the subject possesses that capacity, essentially involves there being something which is seen.

A visual experience is an episode of seeing something only if the experience affords the subject with an awareness of that thing. The object seen is the object of awareness afforded by the subject's visual experience. The function of the visual system is to enable the subject to see the natural environment thus affording the subject awareness of visible aspects of that environment. So the end of sight, that for the sake of which the subject possesses that capacity, essentially involves there being something which is the object of visual awareness. According to $\mathrm{Mc}^{-}$ Dowell $(2010,245)$ this is "a more demanding condition than an experience's being merely veridical", sensible aspects of the natural environment must be present in the awareness afforded by perception. Cases of veridical hallucination, if genuinely possible, are precisely cases where the subject's sensory experience is veridical, but the veridical subject matter of that experience is not present in sensory awareness. It is because this more demanding condition is met that there is no possibility consistent with the subject's perceptual experience being what it is that the subject could be wrong in judging that the natural environment is as their experience presents it to be. If a pig is present in the awareness my visual experience affords me of the scene, then there is no possibility compatible with the way that experience is, essentially involving as it does a porcine presence, that there is no pig to be seen, recognized, and remarked upon.

Not all conscious exercises of the subject's perceptual capacities afford such awareness. Due to simultaneous color contrast, a brown thing may look bright orange. Moreover, there may be no way for the perceiver to know that their experience is not the presentation of something bright orange merely by reflecting on 
their visual experience as given in introspection. A visual experience of a brown thing looking bright orange is the conscious exercise of the subject's capacity for sight, but there is nothing bright orange of which the subject is aware. Similarly, hallucinating a pig is an experience that draws upon the subject's capacity for sight. It is a conscious exercise of the subject's perceptual capacities, but it affords the subject with awareness of nothing. Our perceptual capacities are thus fallible, sometimes tragically and dramatically so.

On the present proposal, defective exercises of the subject's perceptual capacities are defective in the sense that the end of the capacity, what that capacity is a potential for, goes unrealized. Since the function of the perceptual system is to enable the subject to perceive the environment, to present sensible aspects of the natural environment in sensory awareness, defective exercises of the subject's perceptual capacities are not perceptions and afford no such awareness, otherwise they would be non-defective. The present point is that experiences which are the defective exercise of the subject's perceptual capacities have a purely negative characterization. Defective exercises fail to achieve what the capacity is a potential for. But there are indefinitely many ways in which a capacity may be drawn upon and not achieve what it is a potential for. What unity there is to experiences which are the defective exercises of the subject's perceptual capacities is entirely given by their being the conscious exercise of a perceptual capacity that fails to achieve its end, to present sensible aspects of the natural environment in sensory awareness.

A supplementary argument provides partial corroboration. The initial premise is an identification: Sense experience just is the conscious exercise of a subject's perceptual capacities. Sense experience thus ontologically depends upon the subject's perceptual capacities. After all, what it is for the subject to undergo an episode of sensory experience just is for them to undergo a conscious exercise of their perceptual capacities. But ontological dependence is transitive:

The Transitivity of Ontological Dependence: If $x$ ontologically depends upon $y$, and $y$ ontologically depends upon $z$, then $x$ ontologically $\mathrm{de}^{-}$ pends upon $z$.

Thus, by the transitivity of ontological dependence, sense experience ontologically depends upon perception. What it is to undergo an episode of sensory experience just is to undergo a conscious exercise of the subject's perceptual capacities, and what it is for a subject to possess such capacities just is their potential to perceive. If perception wears the trousers in drawing the defective/non-defective distinction, if there is no unity to defective exercises of perceptual capacities that goes beyond being conscious exercises of perceptual capacities that fail to achieve the end of presenting aspects of the natural environment in sensory awareness, then the ontological dependence of sense experience on sense perception is not only intelligible, but mandatory. 
According to experiential monism, sense experience has a single common nature. The Cambridge realists in maintaining that all sense experience involves, as part of its nature, a sensory mode of awareness were committed to a kind of experiential monism. Not only is the sense-datum theory a kind of experiential monism, but so is the Stuff-Happens model. On the Stuff-Happens model, the subject's perception of an object is determined by a state of the perceptual system which is the terminal state of a sequence of alterations initiated by the proximal stimulation of sensory transducers. However, the subject's perceptual system could be in that state even if the relevant object were absent. So the possible states of the perceptual system must be able to carry not only information, but misinformation. Moreover, the sense experience determined by the perceptual system being in that state when the object is absent would be indiscriminable upon reflection from the experience determined by that state when the object was present. On the Stuff-Happens model, every sense experience has a common nature in that each is determined by one of a range of possible states of the subject's perceptual system, where the possible states of the perceptual system correspond to the conscious character of sense experiences that the subject may undergo.

Experiential pluralism is the denial of experiential monism. On the present view, sense experiences belong to two mutually exclusive and exhaustive kinds. One kind of sense experience constitutes the perception of some sensible aspect of the natural environment where this involves, as part of its nature, the presentation of that aspect in the awareness afforded by perceptual experience. This is distinguished as a fundamental kind of sense experience in that perception is what perceptual capacities are the potential for. The first kind of sense experience is not only ontologically prior to the perceptual capacity whose exercise it is, but the general notion of sense experience ontologically depends upon perception as well. Sense experiences belonging to the second kind are not perceptions. While exercises of the subject's perceptual capacities, they do not achieve the end of presenting some aspect of the natural environment in sensory awareness. The purely negative characterization of the latter kind guarantees that the resulting distinction is both mutually exclusive and exhaustive. A commitment of this is that two sense experiences being indiscriminable upon reflection is insufficient for their being the same kind. One may be a perception of the subject's environment whereas the other may be a matching hallucination, say. But these experiences differ in kind, the first achieves the end of perception whereas the second does not. The first involves, as part of its nature, the presentation of some aspect of the natural environment in the awareness afforded by the subject's visual experience. The second involves no such presentation and so must differ in nature. This is a kind of experiential pluralism. Thus if sight is for the sake of seeing, sight depends upon seeing in a manner that is inconsistent with experiential monism. 
Compare the present view with the sense-datum theory. A putative insight moves Moore's sense-datum theory-sense experience is to be understood, fundamentally, as a kind of sensing, where sensing is, or at least affords, awareness of something. Sensing is thus fundamental to sense experience. Moreover it is fundamental in this sense: All sense experience involves, as part of its nature, the sensing of something, a sensory mode of awareness. The present view partly agrees with the sense-datum theory. Specifically, at least some sense experiences-perceptual experiences - are to be understood, fundamentally, in terms of sensing. Perception is, after all, a sensory mode of awareness. There is another, perhaps less obvious, commonality between the present view and the sense-datum theory. The present view agrees with Moore that sensing is fundamental to sense experience. The present view and the sense-datum theory merely disagree about the way in which sensing is fundamental. According to the sense-datum theory, sensing is fundamental to sense experience by being the common mental element of all sense experience. So conceived, sense experience has a single common nature. The sense-datum theory is thus a form of experiential monism. However, sensing may be fundamental to sense experience without commitment to experiential monism. On the present view, sensing is fundamental to sense experience not by being the common mental element of all sense experience, but by being that upon which sense experience ontologically depends. What it is to undergo an episode of sensory experience just is to undergo a conscious exercise of the subject's perceptual capacities, and what it is for a subject to possess such capacities just is their potential to perceive. It is in this way that sensing is fundamental to sense experience. However, on the present view, only perceptual experience involves, as part of its nature, a sensory mode of awareness. Only perceptual experiences are sensings. A defective exer cise of the subject's perceptual capacities does not achieve the end of presenting some aspect of the natural environment in sensory awareness. Defective exercises of the subject's perceptual capacities are defective precisely in failing to sense the environment. Such experiences must be distinct in nature even from perceptual experiences indiscriminable upon reflection from them. This is a form of experiential pluralism.

Not only can Moore's insight that sensing is fundamental to sense experience be accommodated consistently with the rejection of experiential monism, but reflection on the power of perception warrants a stronger claim. Suppose perception is identified with sense experience that meets further external constraints (that the sense experience is both veridical and caused by, or counterfactually depends upon, in the right sort of way, its veridical subject matter, say). Then perception will ontologically depend upon sense experience. What it is to undergo an episode of seeing just is to undergo a visual experience that meets these constraints. Moreover, since the being of the former wholly consists in the being of the latter, not only 
would seeing ontologically depend upon visual experience, but visual experience would be ontologically prior to seeing as well. But if seeing is the non-defective exercise of the subject's capacity for sight, visual experience ontologically depends upon seeing in a manner inconsistent with the ontological priority of visual experience. Thus, reflection on the power of perception reveals a pattern of dependence between perceptual capacitities and their exercise that is inconsistent with experiential monism.

\section{References}

Jonathan Barnes. The Complete Works of Aristotle, Volume II, The Revised Oxford Translations. Bollingen Series. Oxford University Press, Oxford, I984. I2

Bill Brewer. Perception and Its Objects. Oxford. Oxford University Press, 20II. 5

Tyler Burge. Disjunctivism and perceptual psychology. Philosophical Topics, 33(I): $\mathrm{I}^{-} 78$, Spring $2005 \cdot 4,5$

Tyler Burge. Origins of Objectivity. Oxford University Press, Oxford, 2OIO. 2, I2

John Campbell. Demonstrative reference, the relational view of experience, and the proximality principle. In Robin Jeshion, editor, New Essays on Singular Thought, chapter 6, pages 193-212. Oxford University Press, Oxford, 2010. 4

Gareth Evans. The Varieties of Reference. Oxford University Press, 1982. 2

Kit Fine. Essence and modality. Philosophical Perspectives, 8:I-I6, I994. IO

Kit Fine. Ontological dependence. Proceedings of the Aristotelian Society, 95:269-290, I995. ISSN oo667374. URL http: //www. jstor.org/stable/4545221. 6, 7, io

D.W. Hamlyn. Aristotle De Anima Books II and III (with passages from Book I). Clarendon Press, Oxford, 2002. 3

Mark Johnston. Better than mere knowledge? The function of sensory awareness. In Tamar Szabó Gendler and John Hawthorne, editors, Perceptual Experience, chapter 7, pages 260-290. Clarendon Press, Oxford, 2006. 5

Mark Johnston. On a neglected epistemic virtue. Philosophical Issues, 2I(I):I65-2I8, October 20II. doi: IO.IIII/j.I533-6077.20II.0020I.x. URL http://dx.doi.org/ $10.1111 / j .1533-6077.2011 .00201 . x .5$

Mark Eli Kalderon. Before the law. Philosophical Issues, 2I:219-244, 20II. 5 
Mark Eli Kalderon and Charles Travis. Oxford realism. In Michael Beaney, editor, Oxford Handbook of the History of Analytic Philosophy. Oxford University Press, forthcoming. 5

M.G.F. Martin. The limits of self-awareness. Philosophical Studies, I20:37-89, 2004. I2

John McDowell. Tyler Burge on disjunctivism. Philosophical Explorations, 13(3): 243-255, September 2010. doi: I0.1080/13869795.2010.501905. URL http://dx. doi .org/10.1080/13869795.2010.501905. Unpublished manuscript. 4, 5, 6, II, I3

G.E. Moore. Some Main Problems in Philosophy. The Muirhead Library of Philosophy. George Allen \& Unwin LTD., London, I953. I

Friedrich Nietzsche. On the Genealogy of Morals: A Polemic. Oxford University Press, I996 edition, I887. 4

Christopher Peacocke. Externalist explanation. Proceedings of the Aristotelian Society, 93:203-230, I993. URL http://www. jstor.org/stable/4545174. 7

H.H. Price. Perception. Methuen \& CO. LTD., London, I932. I

Gideon Rosen. Metaphysical dependence: Grounding and reduction. In Bob Hale and Aviv Hoffmann, editors, Metaphysics, Logic, and Epistemology, chapter 6, pages I09-I35. Oxford University Press, Oxford, 20ıо. Iо

Bertrand Russell. The Problems of Philosophy. Home University Library, I9I2. I

Jonathan Schaffer. On what grounds what. In David Chalmers, David Manley, and Ryan Wasserman, editors, Metametaphysics: New Essays on the Foundations of Ontology, chapter I2, pages $347^{-} 383$. Oxford University Press, Oxford, 2009. IO

Paul Snowdon. Hinton and the origins of disjunctivism. In Adrian Haddock and Fiona Macpherson, editors, Disjunctivism: Perception, Action, Knowledge, chapter I, pages 35-56. Oxford University Press, 2008. I

Charles Travis. A sense of occasion. The Philosophical 2uarterly, 55(219):286-314, April 2005a. 5

Charles Travis. Frege, father of disjunctivism. Philosophical Topics, 33(I):307-334, Spring 2005b. 2

Charles Travis. The inward turn. Royal Institute of Philosophy Supplement, 65:313-349, 2009. doi: IO.IOI7/SI358246I09990I54. 2 
Charles Travis. Desperately seeking $\psi$. Philosophical Issues, 2I(I):505-557, 20II. ISSN 1758-2237. doi: I0.IIII/j.1533-6077.2011.002I4.x. URL http://dx. doi.org/10. $1111 / j .1533-6077.2011 .00214 . x .4$

Timothy Williamson. Knoweledge and its Limits. Oxford University Press, 2000. 7 